\title{
A COMPARISON OF GROUND GRID MESH DESIGN AND OPTIMIZATION FOR 500KV SUBSTATION USING IEEE 80-2000 AND FINITE ELEMENT METHODS
}

\author{
Muhammad Usman Cheema ${ }^{1}$, MBilal Cheema ${ }^{2}$, Adnan Bashir $^{3}$, M Usman Aslam ${ }^{4}$ \\ Electrical Engineering Department, University of Engineering \& Technology \\ Lahore,Pakistan $^{1}$ \\ Electrical Engineering Department, Bahria University Islamabad, Pakistan ${ }^{2}$ \\ Electrical Engineering Department, University of Engineering \&Technology \\ Lahore,Pakistan ${ }^{3}$ \\ Electrical Engineering Department, University of Engineering \& Technology Lahore \\ Pakistan $^{4}$
}

\begin{abstract}
An Air Insulated substation is chosen for the analysis located in Pakistan. The protective scheme installed in any substation should be fully active to ensure its proper and accurate operation in case of any fault. Ground Grid mesh used under substation ground consist of horizontal conductors connected with vertical rods. The function of mesh is to dissipate extremely high current generated in any scenario related to fault. In this regard, firstly $500 \mathrm{KV}$ substation is chosen for analysis of protection scheme with focus especially on Ground Grid mesh. The analysis of mesh is carried out using both IEEE 80-2000 and Finite Element Methods for the evaluation of important ground grid mesh parameters. A Software is used for analysis i.e. ETAP -12 having more enhanced features than previous versions. The problems regarding existing functioning ground grid mesh are brought to light in one case study. In second Case study, the remedies for the rectification of mesh are provided. In third, case study a new ground mesh is designed for the existing substation considering new methodologies and latest analysis techniques. In fourth case study, a new ground mesh for Ultra High Voltage Substation is designed for $750 K V$ substation. Finally, a inter comparison is done between mesh designed using IEEE 80-2000 and FEM methods to effectively establish the efficiency and effectiveness of each method by each Case study. A recommendation is given regarding the best method to be used for the future designing of ground grid mesh of all AIS substations.
\end{abstract}

Key Terms: Electrical Transient Analysis Program, National Transmission and Dispatch Centre, Potential Ground Rise, Ground grid System

\section{Introduction}

The appropriate explanation of grounding described as link created intentionally or unintentionally along live apparatus /part which itself connects to electrode laid at suitable depth below substation ground and it functions as earthing electrode.

DOI : $10.14810 /$ elelij.2015.4111 
The scheme used for HV systems grounding is solidly grounded structure [1, 2]. The value of resistance among ground earth and neutral of system is retained at low level as it is difficult to attain zero value. The current due to ground fault peaks at a high level which is damaging. The problems like stress due to high fault currents do not arise often.

The insulation related problems are the major concern in high voltage systems but in system grounded properly by employing solid grounded scheme, upon line and ground fault occurrence voltage does not rise massively across healthy phases. The fault current value for $500 \mathrm{KV}$ system is $40-45 \mathrm{KA}$ and for $750 \mathrm{KV}$ system value is between $60-70 \mathrm{KA}$.

The protective scheme design is an important aspect in design and construction of substation. The voltage gradients are created across ground mesh and points linked to earth as reference [3]. The difference in potential is kept within the limits provided by IEEE and it is continuously monitored for the equipment proper functionality and people safety working in surrounding.

The vital factors required for ground grid mesh evaluation are GPR,Voltage $S_{\text {tep }}$, Voltage StepV $_{t}$, Resistance of Ground Rg , Voltage MeshV $_{\mathrm{m}}$,ESP \& Potential Absolute. There are various methods available for designing of ground mesh for substation. IEEE 80-2000 and FEM methods are adopted for mesh designing in research conducted as these are more reliable ones. The collection of data is carried out for $500 \mathrm{KV}$ substation by making use of new available IEEE 81 methods. The mesh modeling is carried out and analysis is performed by each methods mentioned above. The GGS module in ETAP-12 data is used for ground grid mesh modeling.

The inter-comparison of FEM \& IEEE 80-2000 results is done of various case studies developed on existing ground grid mesh to establish the effectiveness in terms of cost\& efficiency of each method. The recommendations are made regarding the methods upon which the future designing of ground grid mesh for substations may be based upon.

\subsection{IEEE $81{ }^{2013}$ Methods}

IEEE has provided latest set of methods for measurement of various potentials, resistivity and ground resistance [3,4].These methods are called IEEE 81 methods launched in 2013.The main aim for the development of these methods was to eradicate the deficiencies in various measurement techniques used for collection of practical data from the site where ground grid mesh is about to be constructed or from area where ground grid mesh is already laid and functioning. The remedial actions were related to false measuring techniques, errors related to the equipment and human errors readings slip-ups.

These all things were taken into account by a committee formed to address these problems. The recommendations were forwarded by the committee to the council and upon those proposals IEEE 81 methods were adopted.

IEEE 81-1983 methods were previously utilized used for soil resistivity and resistance before making use of IEEE 81 standard. All measurements are taken by making use of IEEE 81 methods in current project \& afterwards further modeling is done based on available data. 


\subsection{Resistivity of Soil Measurement}

The ground mesh design is difficult practice comprising numerous stages. The data collection of area substation is to be created is an important part. A comprehensive test is carried out during data collection phase for information like layers in number, soil type, resistivity of soil and soil stratification whether soil is horizontally or vertically stratified $[2,3]$.

The soil resistivity is calculated by using methods given as:
A.Schlumberger
B.Three Point Driven Rod
C.four Point
D.wenner

The resistivity calculation can be made by any one of above method but Driven Rod/3 point is consistent method adopted for soil resistivity calculation shown in figure 1.

In this method, the depth 'Lr' of the driven-rod located in the soil to be tested is varied. The other two rods, known as reference rods are driven to a shallow depth in a straight line. The location of the voltage rod is varied between the test rod and the current rod. Alternately, the voltage rod may be placed on the side opposite the current rod. The apparent resistivity is given in equation 1.

$$
\rho_{a}=\frac{2 \pi L_{r} R}{\ln \left(\frac{8 L_{r}}{d}\right)-1}
$$

Where $\mathrm{Lr}=$ Rod Length in meters, $\mathrm{d}=$ RodDia in meters

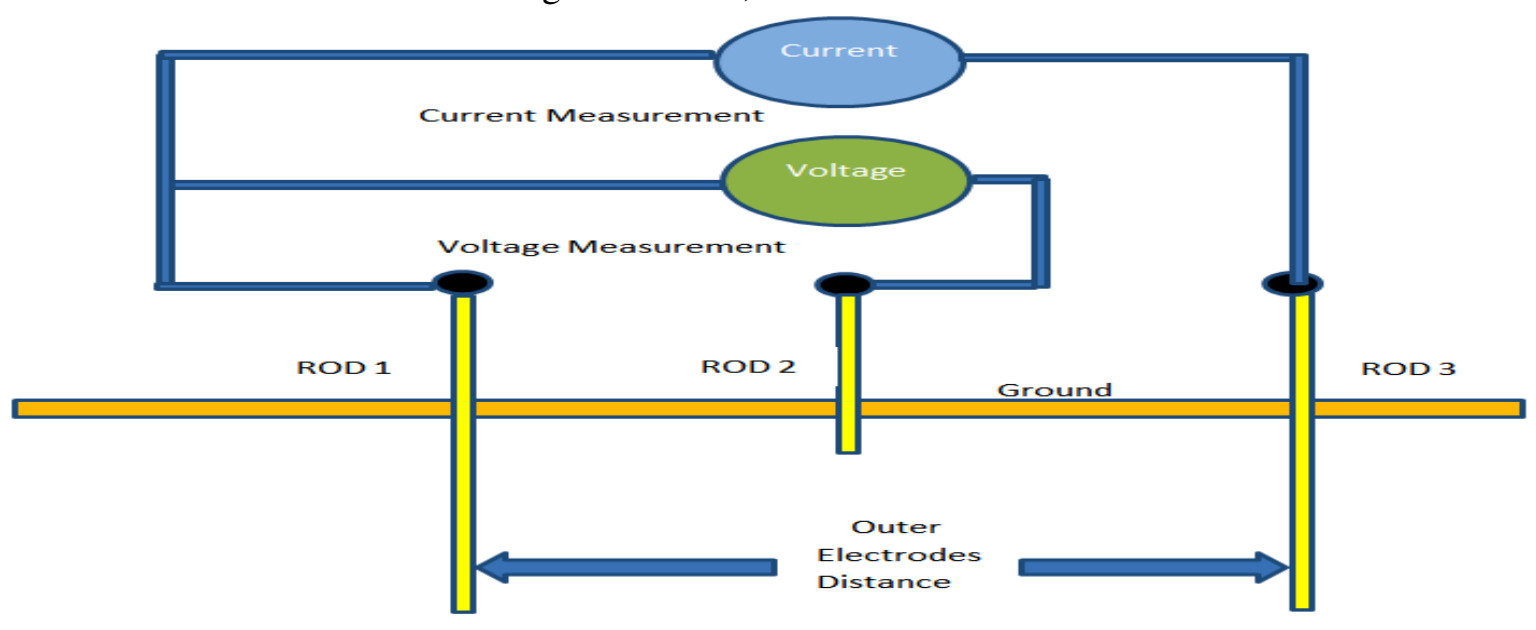

Figure 1 Three Point Driven Rod-Method

\subsection{IEEE 80-2000 Methods}

The 80-2000 methods for calculation of Ground Resistance provided below:

I. Newman-Laurent

II. Shevrak 


\subsubsection{Newman-Laurent Methods}

The soil resistance varies directly with resistivity change. The main objectiveis to approximate a depth defined " $h$ " at which resistance is minimum $[3,4]$.

The method estimates ground resistance by making use of eq2.

$\mathrm{L}_{\mathrm{a}}=$ Conductors length meters, $\mathrm{N}_{\mathrm{r}}=$ Vertical rods used

$$
\mathrm{Rg}=\rho \frac{1}{4} \cdot \frac{\sqrt{\pi}}{\mathrm{Ag}}+\rho \frac{1}{\mathrm{Ls}} \ldots \ldots \ldots \text { eq } 2
$$

$\mathrm{L}_{\mathrm{s}}$ can be calculated by equation 3

$$
\mathrm{Ls}=\mathrm{La}+\mathrm{Nr} . \mathrm{H} \ldots \ldots \ldots . . \mathrm{eq} 3
$$

\subsubsection{Sevrak Methods}

It is an advance version of Newman- Laurent method incorporating some changes. It is latest version of Newman Method. The adjustment in ground resistance value for surface of soil is carried out for accuracy and improvement of resistance. The deepness of grid has substantial effect on ground resistance calculation. The grid depth effect on resistance was incorporated in existing data. eq 4 provides the formula after necessary modifications.

$$
\begin{aligned}
\operatorname{Rg}= & \rho \cdot\left[\frac{1}{L a}+\frac{1}{\sqrt{20 A}} \cdot\left[1+\frac{1}{1+\frac{h \sqrt{20}}{A g}}\right]\right] \ldots \ldots \text { eq } 4 \\
& \mathrm{~L}_{\mathrm{a}}=\text { Conductors Length }(\mathrm{m}), \mathrm{A}_{\mathrm{g}}=\text { Ground grid area }
\end{aligned}
$$

\subsection{Finite Element Methods}

The Finite Element method is one of the more reliable methods of finding ground grid mesh resistance. The resistance found is fairly close to the actual value, compared to one calculated using conventional measurement methods.

In previous FEM methods, which are outdated now includes analysis of current by making use of potential grid set. After the determination of current, the ground resistance was calculated by dividing the known voltage with the calculated value of current. The drawback of this method was to select model considering that distance of earth to be considered was starting from the grounding grid. The main advantage of this method is selecting the size of the model such as distance of earth under consideration is starting from the grounding grid. Since analysis of each potential in the soil for a selected point is considered from grounding grid to the point [5].

The new FEM methods are available developed by researches with shortcomings in previous methods removed. FEM methods are developed by researchers such as main disadvantage of old FEM method are overcome. In new FEM methods, modeling starts from beginning. In the first step, they assume that grounding resistance is such a parameter which does not depend on potential or current in the grid except frequency cases other from frequencies [6,7] $(50 \mathrm{~Hz}$ or $60 \mathrm{~Hz}$ frequency of power). The second assumption is to consider the whole region as flat surface which is infinite.

The formulas for calculations of Resistances are given below as:

$$
\mathrm{R}=\mathrm{R} 1+\mathrm{R} 2 \ldots \ldots \ldots \ldots \ldots \ldots . . \mathrm{eq} 4
$$


Electrical and Electronics Engineering: An International Journal (ELELIJ) Vol 4, No 1, February 2015

Where $\mathrm{R}$ is the combined resistance sum of resistances of two portions of the flat surfaces

$\mathrm{R} 2$ is calculated from formula given in equation 5 .

$$
\mathrm{R} 2=\frac{p}{2 \pi \cdot d 1}
$$

The R1 is found calculated with eq6.

$\mathrm{R} 1=\frac{\text { Power Disssipated }}{\text { voltage } \mathrm{x} \text { volatge }} \ldots .$. eq6

The potential called actual voltage is found with eq 7 .

$$
\mathrm{V}_{\mathrm{avg}}=\mathrm{I}_{\text {fault. }} . \mathrm{R} \ldots \ldots \ldots . . \mathrm{eq} 7
$$

The boundary voltage is found with eq 8 .

$$
\mathrm{V}_{\mathrm{avg}}=\mathrm{I}_{\mathrm{f}} . \mathrm{R} 2 \ldots \ldots \ldots \text {.eq } 8
$$

\section{Practical Data Collected}

The practical Air Insulated 500KV substation is chosen for the analysis of protection scheme. Ground Grid Mesh of substation will be evaluated to highlight the various essential parameters that are related to developed potentials around the mesh and ground mesh resistance.

The Air Insulated 500KV substation is shown in figure 2.

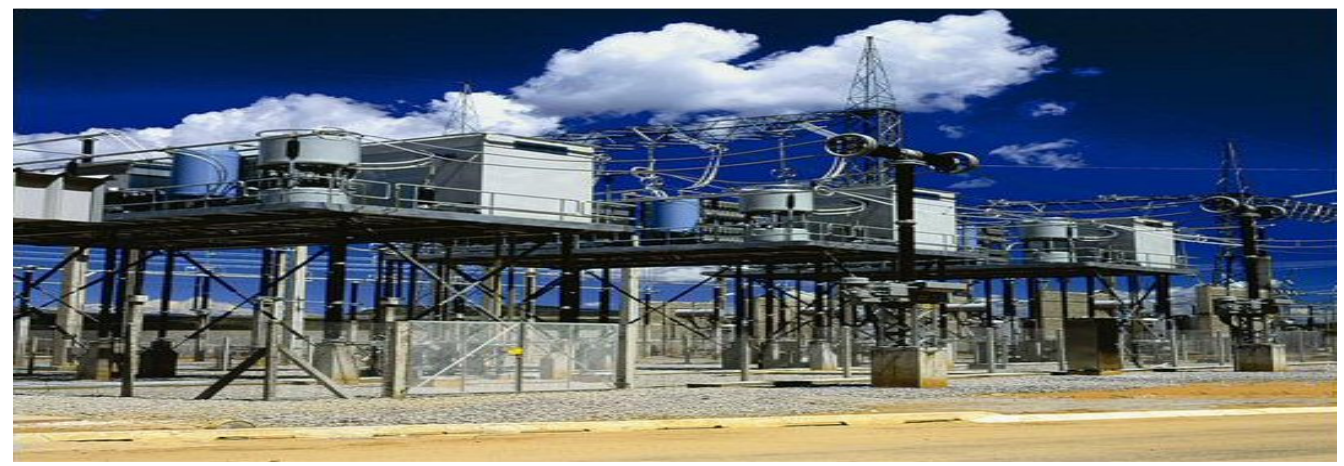

Figure 2 Air insulated Substation

The ground grid mesh modeling incorporating horizontal conductors and vertical rods is shown in figure 3 and the practical data of grid is provided in Appendix-A. 
Electrical and Electronics Engineering: An International Journal (ELELIJ) Vol 4, No 1, February 2015

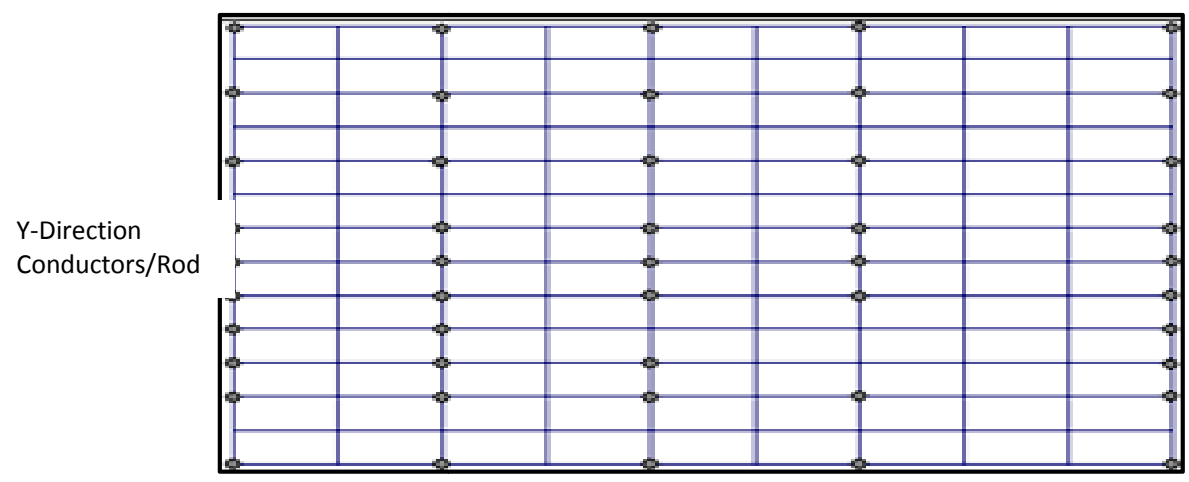

X-Direction Conductors/Rods

Figure 3 Ground Mesh designed in ETAP

\section{Case Studies Comparison using IEEE80-2000 \& FEM Methods}

A strategy is adopted regarding Case Studies comparison in which the ground grid mesh is compared using IEEE 80-2000 \& FEM methods. With the help of results \& material consumption for the establishment of mesh using each methodology, the efficiency \&effectiveness of each method is established $[8,9]$.

\section{Case Study-I IEEE \& FEM Comparison}

The Case study-I is based on the amendments made in existing functioning ground mesh to limit the potentials and temperature rise within the safe limits. The input parameters are provided in table I.

TABLE I. GROUND MESH INPUT DATA CASE -I

\begin{tabular}{|c|c|c|c|}
\hline \multicolumn{2}{|c|}{ Parameters } & IEEE 80-2000 Methods & FEM Methods \\
\hline \multirow{2}{*}{ Length Grid } & x-direction & 144 & 144 \\
\cline { 2 - 4 } & y-direction & 100 & 100 \\
\hline \multirow{2}{*}{$\begin{array}{c}\text { Number of } \\
\text { Conductor }\end{array}$} & x-direction & 20 & 25 \\
\cline { 2 - 4 } & y-direction & 16 & 20 \\
\hline \multicolumn{2}{|c|}{ ConductorsType } & $\begin{array}{c}\text { Soft DrawnCopper } \\
\text { Annealed }\end{array}$ & $\begin{array}{c}\text { Soft DrawnCopper } \\
\text { Annealed }\end{array}$ \\
\hline \multicolumn{2}{|c|}{ Conductor Depth } & 0.3 & 0.3 \\
\hline Conductors Size & 185 & 185 \\
\hline \multicolumn{2}{|c|}{ Number of Rod } & 54 & 57 \\
\hline \multicolumn{2}{|c|}{ Number of Rod } & Steel RodCopper Clad & Steel RodCopper Clad \\
\hline \multicolumn{2}{|c|}{ Rod Diameter } & 1.52 & 1.56 \\
\hline \multicolumn{2}{|c|}{ Length of Rod } & 2 & 2 \\
\hline
\end{tabular}


Electrical and Electronics Engineering: An International Journal (ELELIJ) Vol 4, No 1, February 2015

The results of IEEE 80-2000 \& FEM methods are given in table II with all potentials meeting the limits.

TABLE II. CASE-I COMPARISON RESULTS

\begin{tabular}{|c|c|c|c|c|c|}
\hline $\begin{array}{c}\text { Case } \\
\text { Study }\end{array}$ & Methods & Step Voltage & $\begin{array}{c}\text { Touch } \\
\text { Voltage }\end{array}$ & GPR & $\begin{array}{c}\text { Ground } \\
\text { Resistance }\end{array}$ \\
\hline $\begin{array}{c}\text { Case } \\
\text { Study-I }\end{array}$ & IEEE80-2000 & 1311.1 & 1556.7 & 10139.7 & 0.392 \\
\cline { 2 - 6 } & FEM Methods & 1380.1 & 1248.1 & 9287.5 & 0.37 \\
\hline
\end{tabular}

The graphs for Step, Touch\& Absolute Potential are given in figure 4, 5 \& 6 .

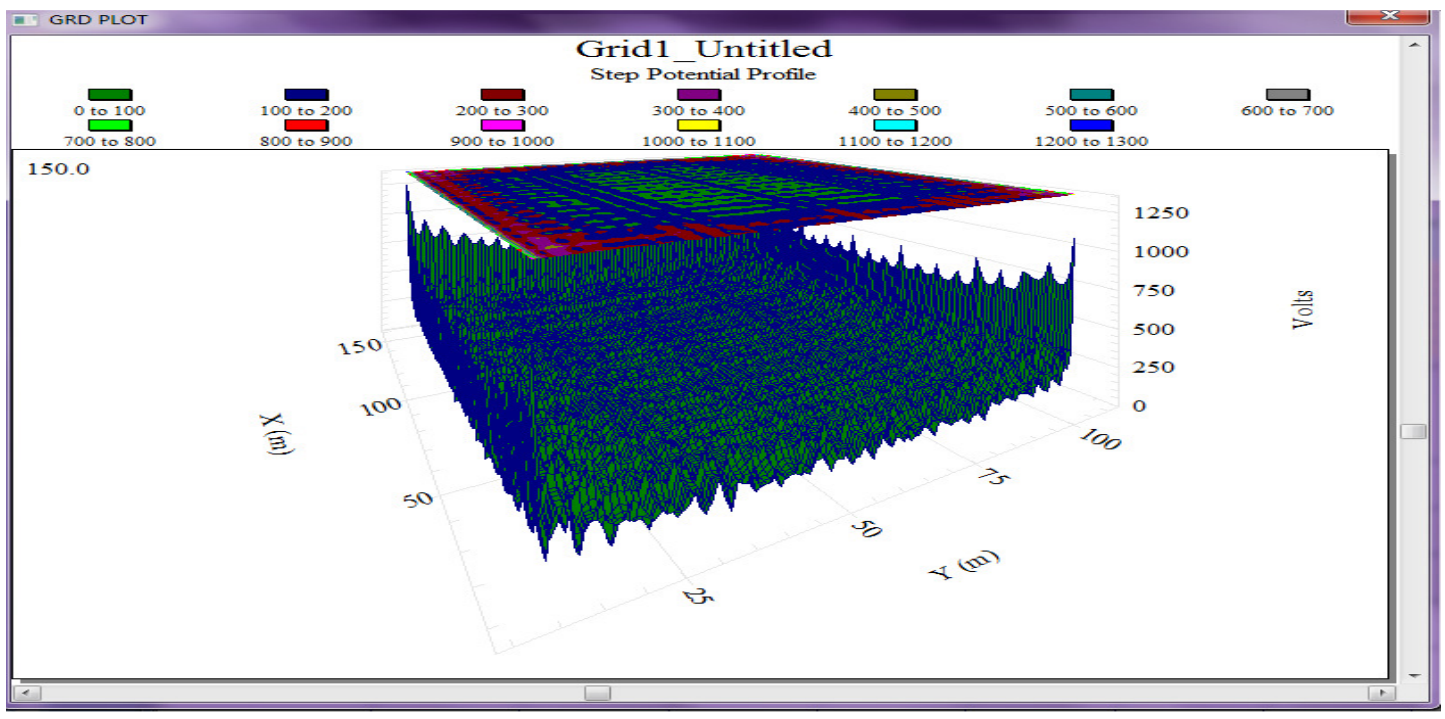

Figure 4 Step Potential

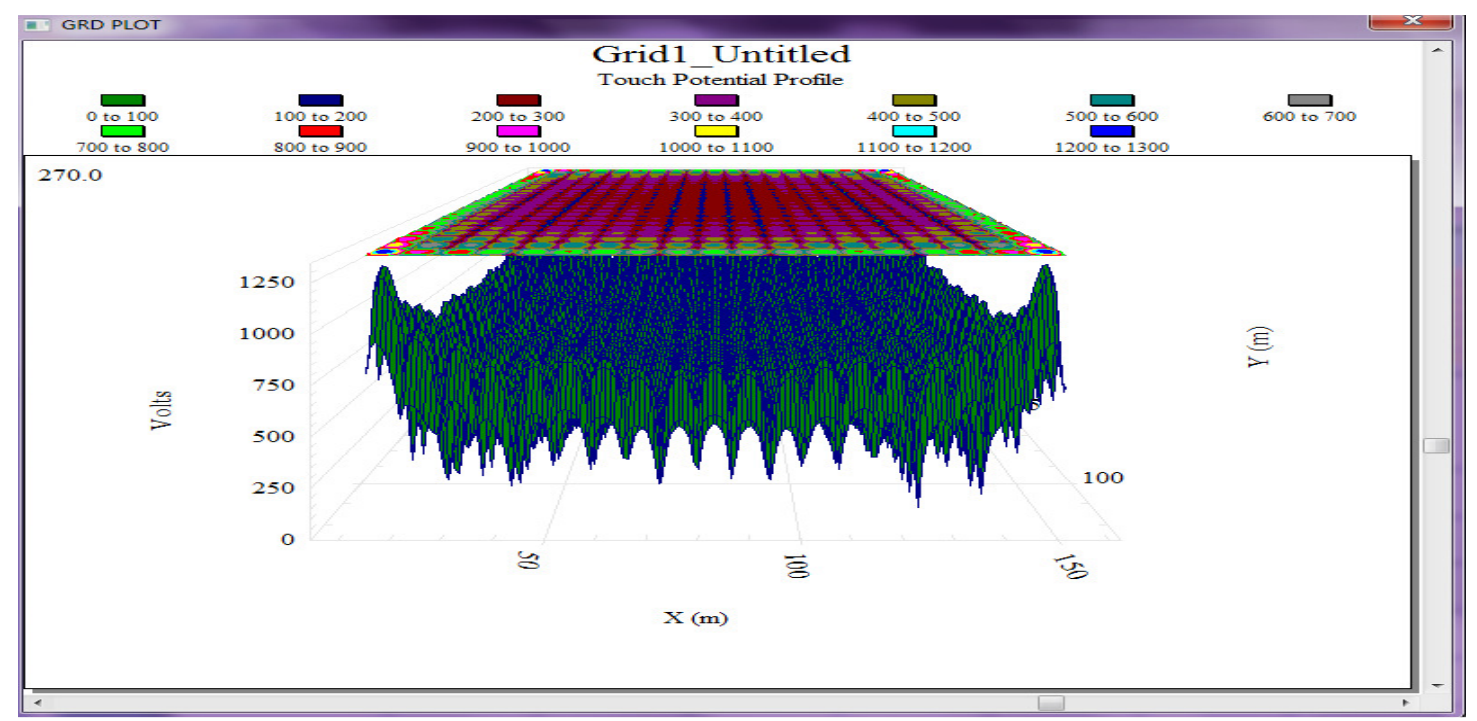

Figure 5 Touch Potential 
Electrical and Electronics Engineering: An International Journal (ELELIJ) Vol 4, No 1, February 2015

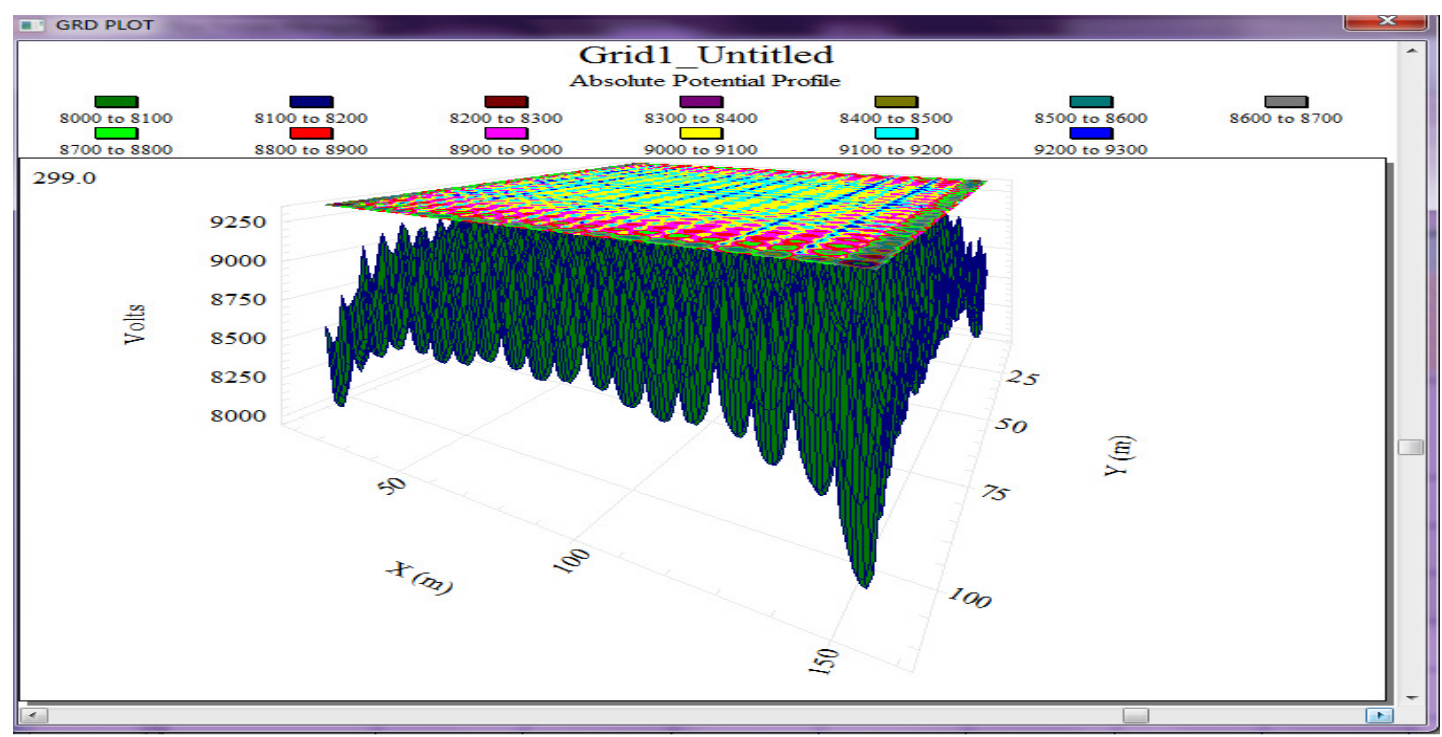

Figure 6 Absolute Potential

\section{Case Study-II IEEE \& FEM Comparison}

The Case study-II is based on planned enhancement in substation level of fault from existing value of 40KA to $45 \mathrm{KA}$. The enhancement is due to replacement of old transformer with new large capacity power transformer.[10] The effect is taken into account in case study with analysis made with both methodologies and necessary amendments are suggested based on each method. The input parameters are provided in table III.

TABLE III. GROUND MESH INPUT DATA CASE -II

\begin{tabular}{|c|l|c|c|}
\hline \multicolumn{2}{|c|}{ Parameters } & IEEE 80-2000 Methods & FEM Methods \\
\hline \multirow{2}{*}{ Grid Size Length } & X-Direction & 144 & 144 \\
\cline { 2 - 4 } & y-direction & 100 & 100 \\
\hline \multirow{2}{*}{ Number of Conductor } & x-direction & 22 & 29 \\
\cline { 2 - 4 } & Y-Direction & 19 & 26 \\
\hline \multirow{2}{*}{ Conductors Type } & \multicolumn{2}{|c|}{$\begin{array}{c}\text { Soft Drawn Copper } \\
\text { Annealed }\end{array}$} & $\begin{array}{l}\text { Soft DrawnCopper } \\
\text { Annealed }\end{array}$ \\
\hline Conductors Depth & 0.3 & 0.3 \\
\hline Conductors Size & 185 & 185 \\
\hline \multicolumn{2}{|c|}{ Number of Rod } & 65 & 60 \\
\hline \multicolumn{2}{|c|}{ Number of Rod } & SteelRodCopper Clad & Steel RodCopper Clad \\
\hline \multicolumn{2}{|c|}{ Rod Diameter } & 1.61 & 1.63 \\
\hline Length of Rod & 2 & 2.1 \\
\hline
\end{tabular}

The results of IEEE 80-2000 \& FEM methods are given in table IV. 
Electrical and Electronics Engineering: An International Journal (ELELIJ) Vol 4, No 1, February 2015

TABLE IV. CASE-II COMPARISON RESULTS

\begin{tabular}{|c|c|c|c|c|c|}
\hline $\begin{array}{c}\text { Case } \\
\text { Study }\end{array}$ & Methods & StepVoltage & $\begin{array}{c}\text { Touch } \\
\text { Voltage }\end{array}$ & GPR & $\begin{array}{c}\text { Ground } \\
\text { Resistance }\end{array}$ \\
\hline $\begin{array}{c}\text { Case } \\
\text { Study-II }\end{array}$ & IEEE80-2000 & 1747.3 & 1307.3 & 11332.8 & 0.39 \\
\cline { 2 - 6 } & FEM Methods & 1538.9 & 1323.6 & 10677.1 & 0.367 \\
\hline
\end{tabular}

The graphs for Step, Touch and Absolute Potential are given in figure 7,8 \& 9 .

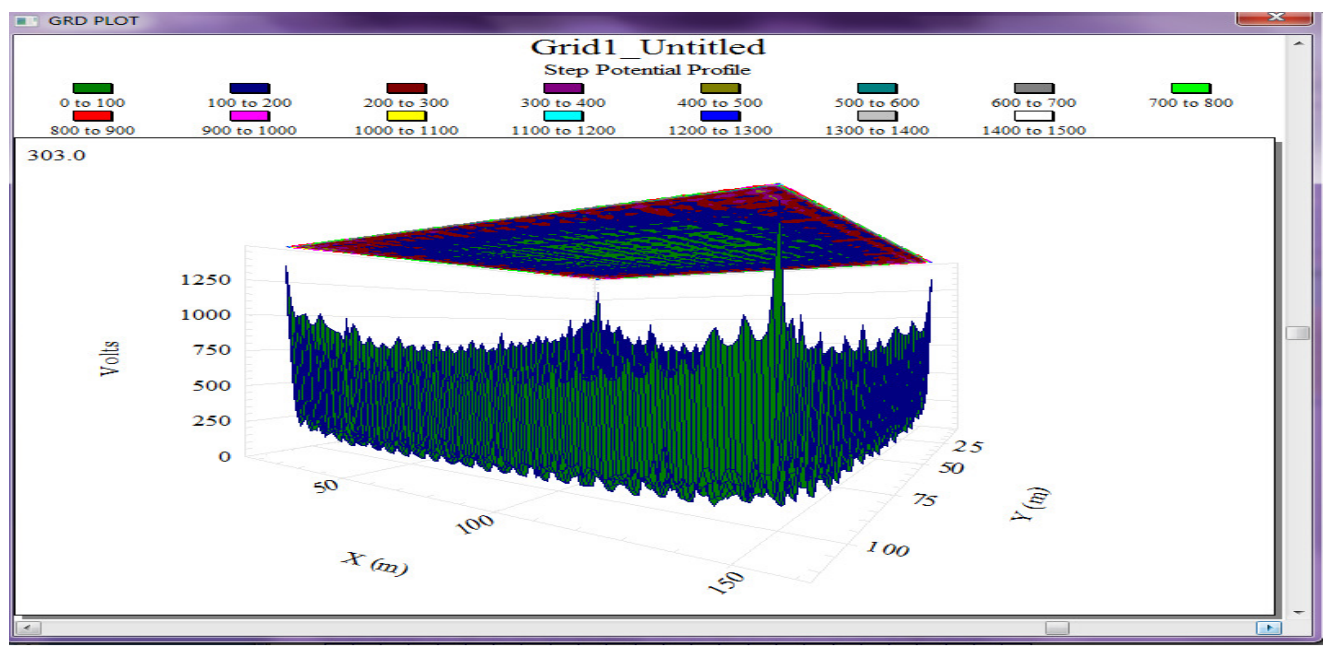

Figure 7 Step Potential

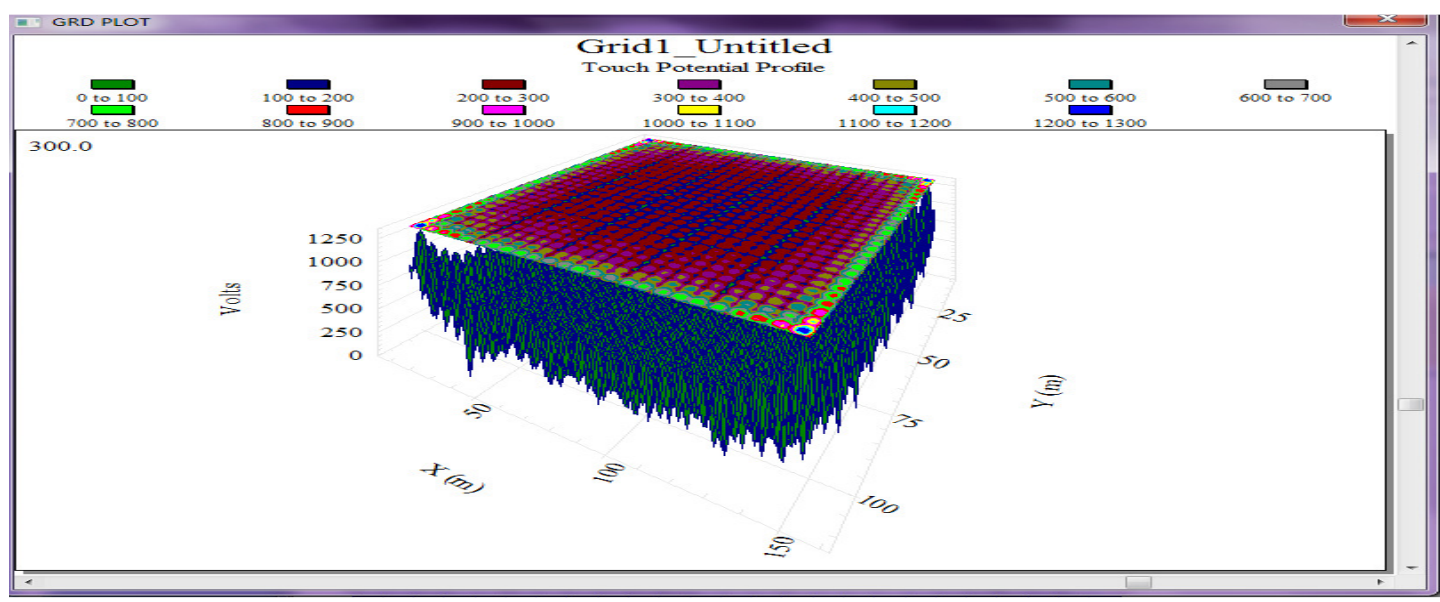

Figure 8 Touch Potential 
Electrical and Electronics Engineering: An International Journal (ELELIJ) Vol 4, No 1, February 2015

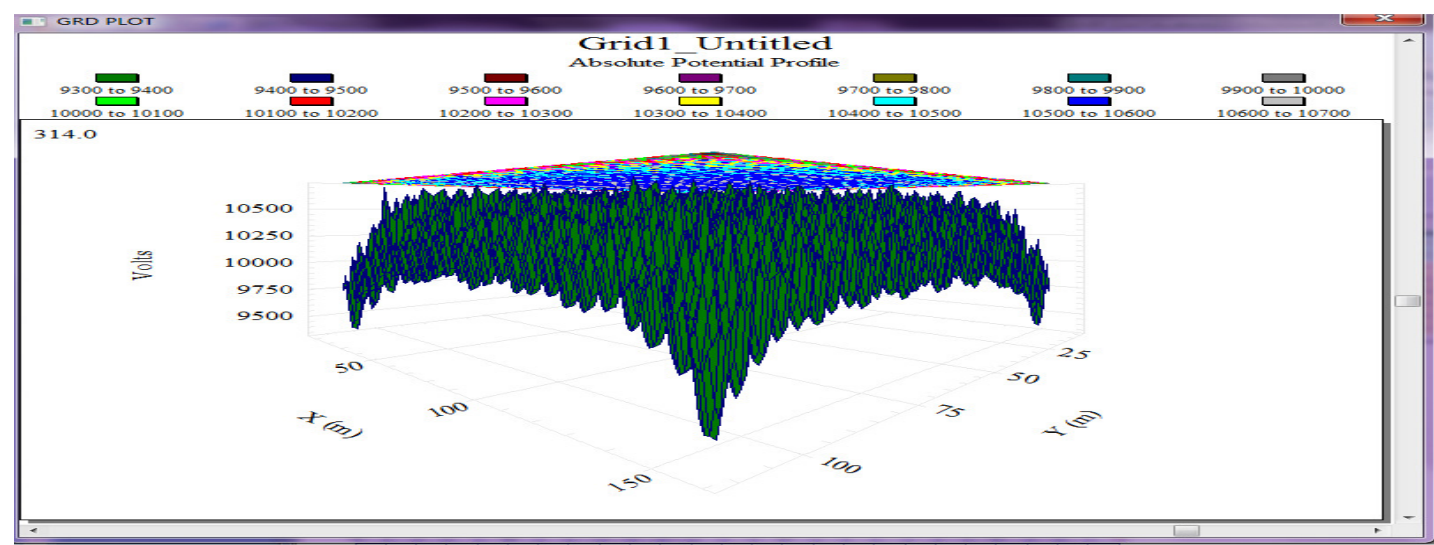

Figure 9 Absolute Potential

\section{Case Study-III IEEE \& FEM Comparison}

The Case study-III is based on re-designing of whole substation grounding scheme using latest optimization techniques based on IEEE 80-2000 \& FEM methods as latest advancement in technology has led to improvement in overall ground mesh designing [11,12].The input parameters are provided in table $\mathrm{V}$.

TABLE V. GROUND MESH INPUT DATA CASE-III

\begin{tabular}{|c|c|c|c|}
\hline \multicolumn{2}{|c|}{ Parameters } & IEEE 80-2000 Methods & FEM Methods \\
\hline Length Grid & x-direction & 120 & 120 \\
\cline { 2 - 4 } & y-direction & 83 & 83 \\
\hline \multirow{2}{*}{ Conductor Number } & x-direction & 22 & 26 \\
\cline { 2 - 4 } & y-direction & 12 & 22 \\
\hline \multicolumn{2}{|c|}{ ConductorsType } & $\begin{array}{c}\text { Soft DrawnCopper } \\
\text { Annealed }\end{array}$ & $\begin{array}{c}\text { Soft DrawnCopper } \\
\text { Annealed }\end{array}$ \\
\hline \multicolumn{2}{|c|}{ Depth of Conductors } & 0.7 & 0.5 \\
\hline \multicolumn{2}{|c|}{ Size of Conductors } & 185 & 240 \\
\hline \multicolumn{2}{|c|}{ Number of Rod } & 42 & 50 \\
\hline Number of Rod & Copper Clad SteelRod & Copper Clad Steel Rod \\
\hline \multicolumn{2}{|c|}{ Rod Diameter } & 1.6 & 1.56 \\
\hline \multicolumn{2}{|c|}{ Length of Rod } & 2 & 2.5 \\
\hline
\end{tabular}

The results of IEEE 80-2000 \& FEM methods are given in tableVI.

TABLE VI.CASE-II COMPARISON RESULTS

\begin{tabular}{|c|c|c|c|c|c|}
\hline Case Study & Methods & StepVoltage & Touch Voltage & GPR & $\begin{array}{c}\text { Ground } \\
\text { Resistance }\end{array}$ \\
\hline $\begin{array}{c}\text { Case Study- } \\
\text { III }\end{array}$ & IEEE80-2000 & 981.5 & 1295.8 & 12053.8 & 0.466 \\
\cline { 2 - 6 } & FEM Methods & 1218.7 & 1329.8 & 10367.2 & 0.438 \\
\hline
\end{tabular}

The graphs for Step and Absolute Potential are given in figure 10,11, \& 12. 
Electrical and Electronics Engineering: An International Journal (ELELIJ) Vol 4, No 1, February 2015

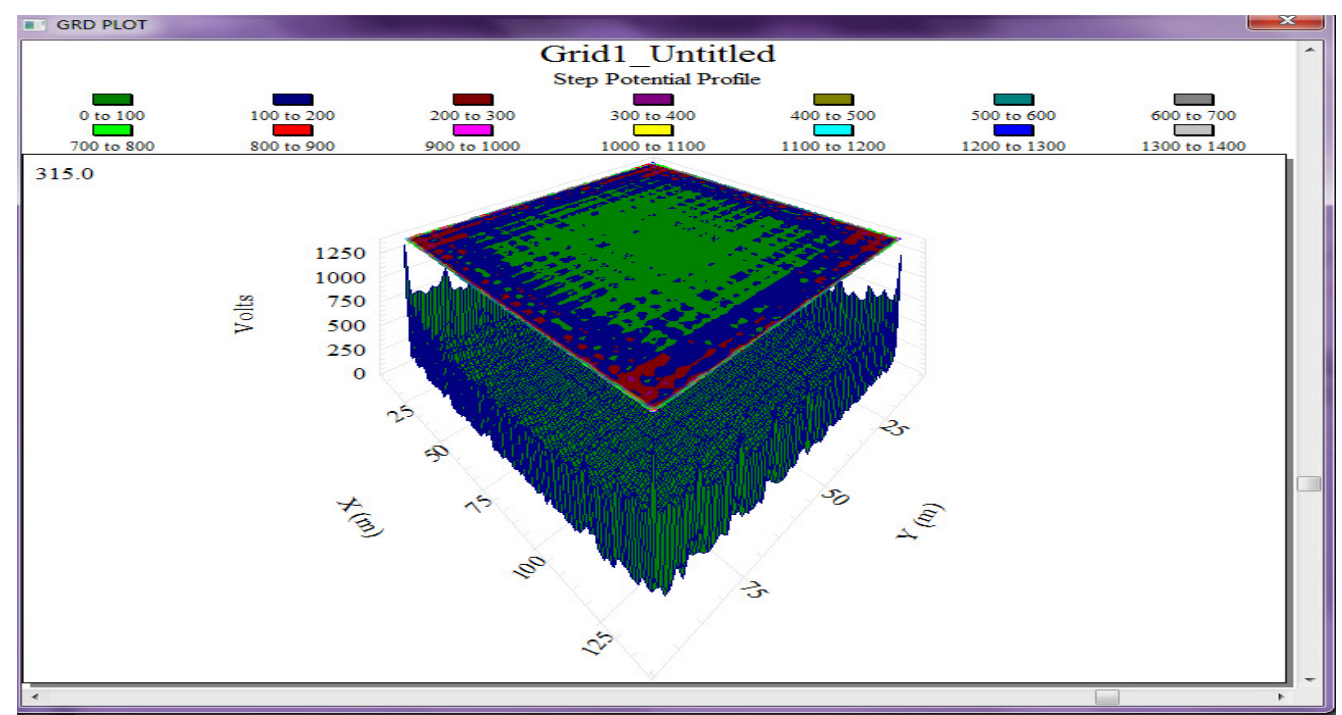

Figure 10 Step Potential

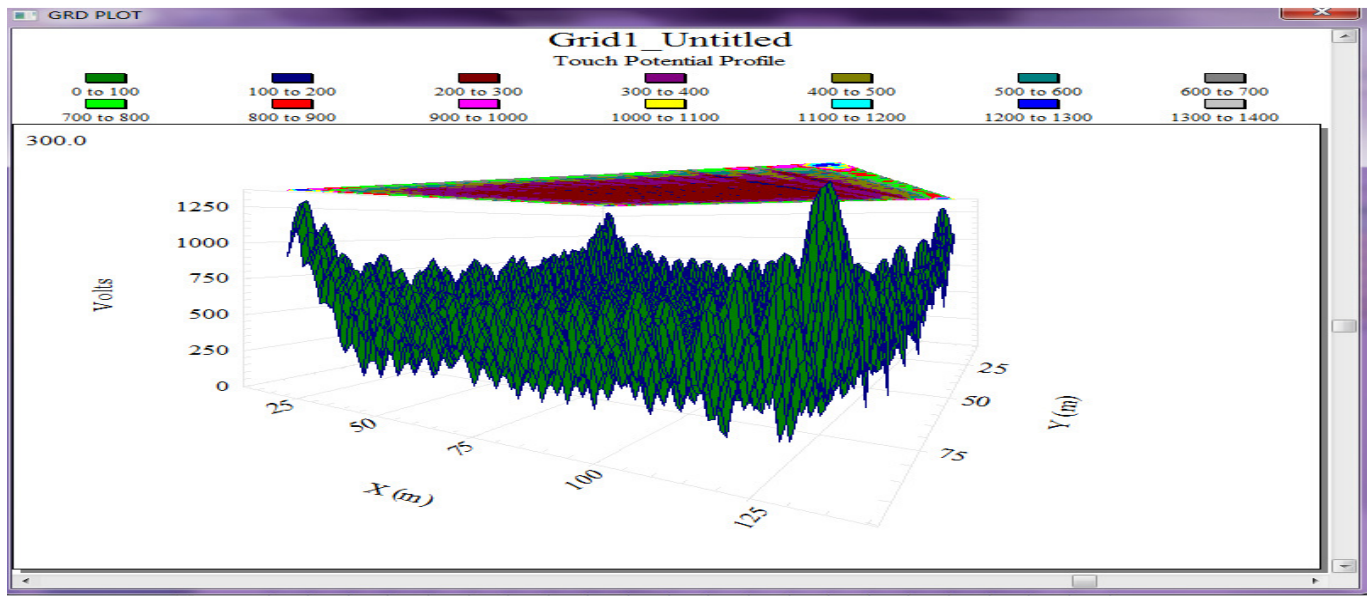

Figure 11 Touch Potential

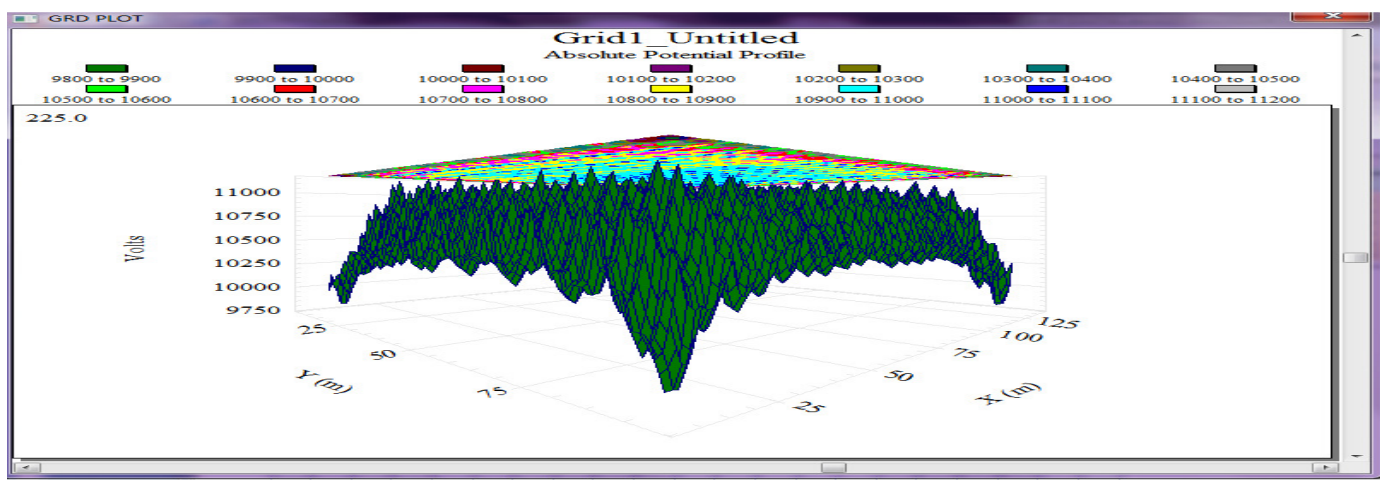

Figure 12 Absolute Potential 
Electrical and Electronics Engineering: An International Journal (ELELIJ) Vol 4, No 1, February 2015

\section{Case Study-IV IEEE \& FEM Comparison}

The Case study-III is based on new $750 \mathrm{KV}$ mesh of substation to be included in system in future. The soil characteristics obtained for $500 \mathrm{KV}$ substation will be used for further designing of $750 \mathrm{KV}$ substation. The designing will be based on IEEE 80-2000 \& FEM methods incorporating optimization techniques.

The input parameters are provided in table VII.

TABLE VII. GROUND MESH INPUT DATA CASE-IV

\begin{tabular}{|c|c|c|c|}
\hline \multicolumn{2}{|c|}{ Parameters } & IEEE 80-2000 Methods & FEM Methods \\
\hline \multirow{2}{*}{ Length Grid } & x-direction & 150 & 150 \\
\cline { 2 - 4 } & y-direction & 70 & 120 \\
\hline \multirow{2}{*}{ Conductor Number } & x-direction & 30 & 31 \\
\cline { 2 - 4 } & y-direction & 22 & 37 \\
\hline \multirow{2}{*}{ Conductor Type } & Soft DrawnCopper Annealed & $\begin{array}{c}\text { Steel RodCopper } \\
\text { Clad }\end{array}$ \\
\hline \multicolumn{2}{|c|}{ Conductors Depth } & 0.8 & 0.8 \\
\hline \multicolumn{2}{|c|}{ Conductors size } & 240 & 240 \\
\hline \multicolumn{2}{|c|}{ Number of Rod } & 42 & 100 \\
\hline \multicolumn{2}{|c|}{ Number of Rod } & steelRodCopper Clad & $\begin{array}{c}\text { SteelRodCopper } \\
\text { Clad }\end{array}$ \\
\hline \multicolumn{2}{|c|}{ Rod Diameter } & 2.1 & 1.6 \\
\hline \multicolumn{2}{|c|}{ Length of Rod } & 2.5 & 2.3 \\
\hline
\end{tabular}

Results of IEEE 80-2000 \& FEM methods are given in table IV.

TABLE VIII.CASE-IV COMPARISON RESULTS

\begin{tabular}{|c|c|c|c|c|c|}
\hline Case Study & Methods & StepVoltage & $\begin{array}{c}\text { Touch } \\
\text { Voltage }\end{array}$ & GPR & $\begin{array}{c}\text { Ground } \\
\text { Resistance } \\
\text { Rg }\end{array}$ \\
\hline \multirow{2}{*}{$\begin{array}{c}\text { Case Study- } \\
4\end{array}$} & IEEE80-2000 & 1090.9 & 1319.1 & $\begin{array}{c}14899 . \\
9\end{array}$ & 0.33 \\
\cline { 2 - 6 } & FEM Methods & 1150.3 & 1525.5 & $\begin{array}{c}11843 . \\
1\end{array}$ & 0.318 \\
\hline
\end{tabular}

The graphs for Step, Touch and Absolute Potential are given in figure 13, 14 \&15 
Electrical and Electronics Engineering: An International Journal (ELELIJ) Vol 4, No 1, February 2015

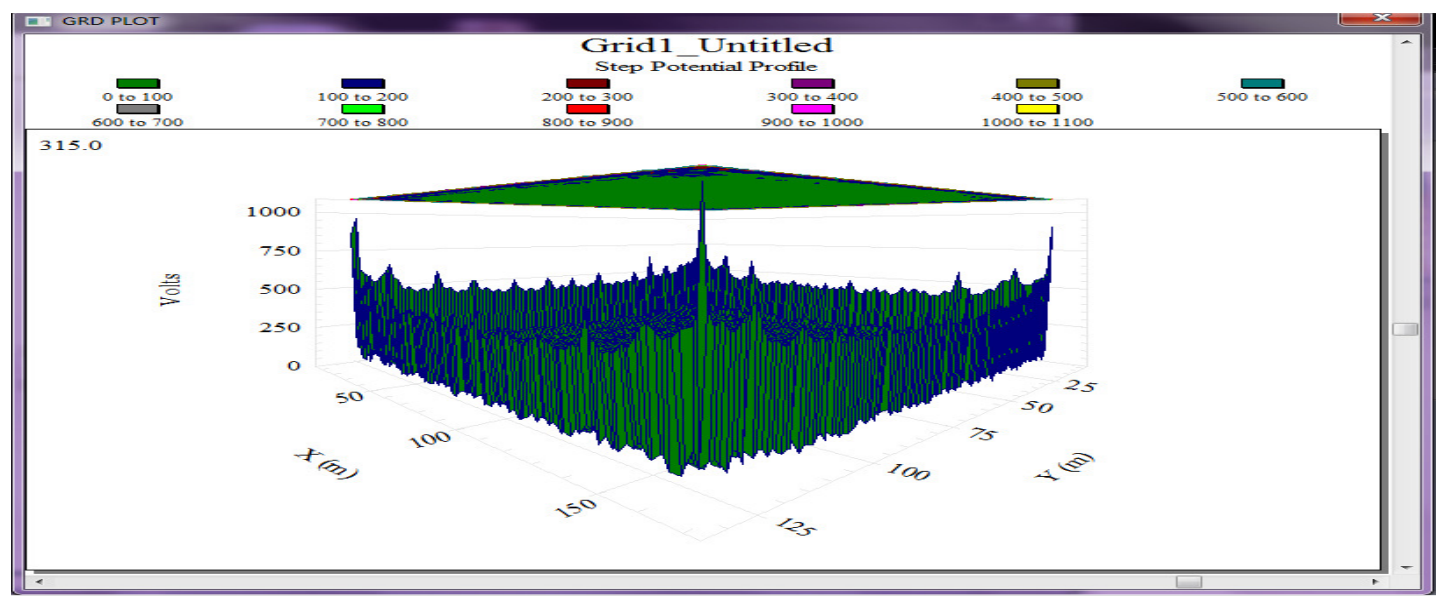

Figure 13 Step Potential

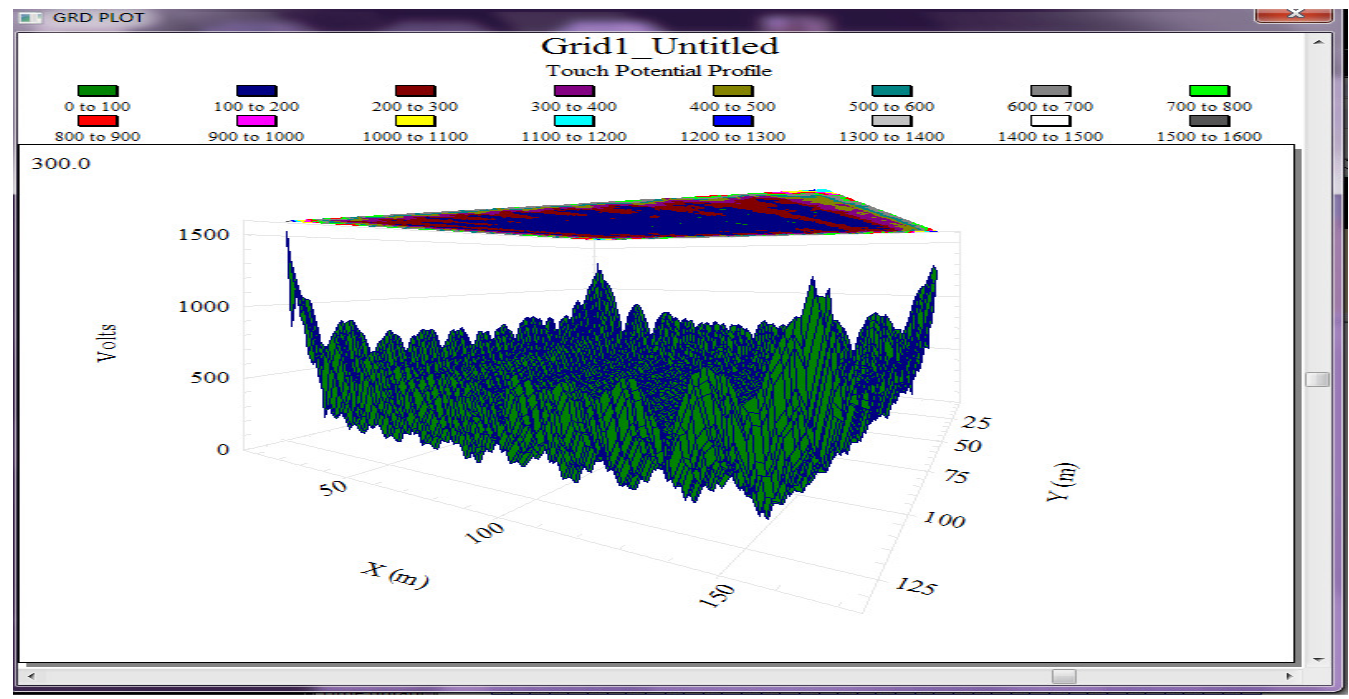

Figure 14 Touch Potential

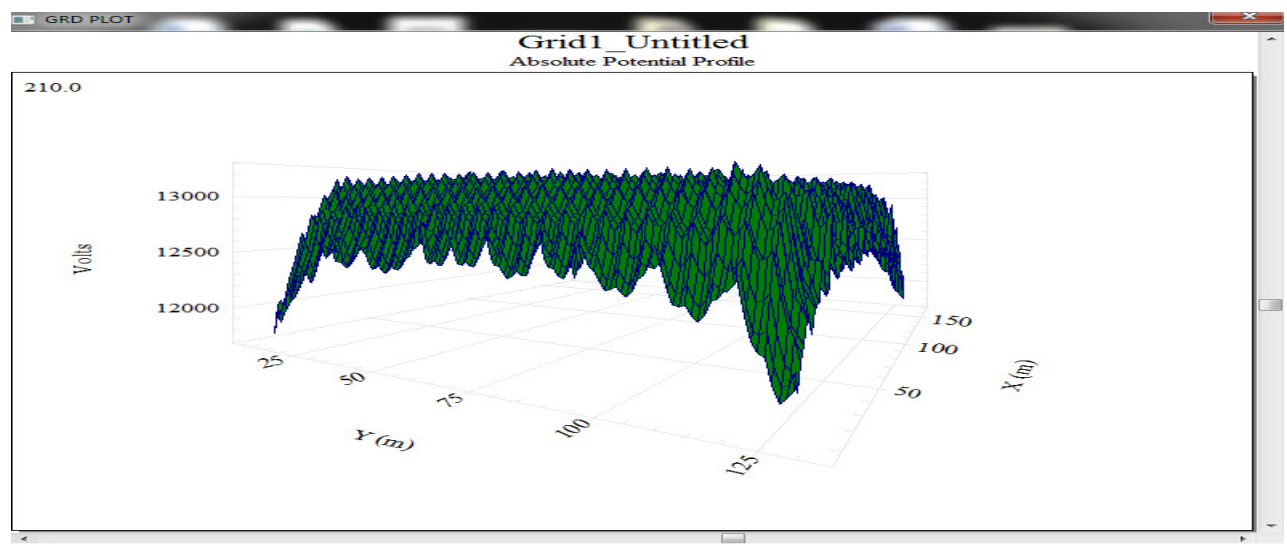

Figure 15 Absolute Potential 
Electrical and Electronics Engineering: An International Journal (ELELIJ) Vol 4, No 1, February 2015

\section{Recommended Analysis Methodology}

The case studies results show that ground mesh structure cost for solution provided by IEEE 802000 methods is less than one designed using FEM methods.

The reason behind the increase cost by FEM is incorporation of number of conductors and rods used for mesh structure. The horizontally laid conductor's surface area is significantly more in mesh designed by FEM. The vertical rod diameter also exceeds the diameter of rods used in 802000 methods $[12,13,14]$.The lower soil layer effect is also included in mesh designed by FEM methods. The proper grounding requirement increases by further lower layer inclusion in design eventually resulting in increase in material consumption for keeping parameters within limits.

\section{Conclusions}

The analysis of mesh was performed with both FEM and 80-2000 methods and also a new ground grid mesh for UHV (750KV Substation) was designed. Latest version of ETAP-12 was used for the verification of results. It can be concluded form obtained results that cost of mesh by FEM remains greater from mesh designed with 80-2000.

First time structure cost will be more for mesh designed by making use of FEM methods but the mesh designed will be more durable, long life and withstand the excessive fault currents more efficiently. The main complications in mesh often come after eight to ten years. The issues are met more in 80-2000 designed mesh. The under designing is the major issue in problematic ground meshes.

Keeping in view future requirements after passage of eight to ten years substations life, mesh degradation occurs and various potentials surpasses limits. It is essential that proper designing of system is carried out using right set of methods to accommodate new requirements and mesh degradation.FEM methods may be used for future designing of mesh.

\section{Acknowledgements}

The Content presented in the paper is part of Research work carried out by Muhammad Usman Cheema for thesis project in connection with partial fulfillment of MSc in Electrical Power Engineering from UET Lahore Pakistan and data submitted to Higher Education Commission Pakistan

\section{References}

[1] The New IEEE Standard Dictionary of Electrical and Electronic Termsll, IEEE Std. 100, USA, 1992.

[2] IEEE Guide for Safety in AC Substation Grounding,ANSI/IEEE Std. 80 (2000). IEEE Society, New York.

[3] IEEE Guide for Measuring Earth Resistivity, Ground Impedance and Earth Surface Potentials of a Grounding System IEEE Std 81 ${ }^{\mathrm{TM}}-2012 / 2013$.

[4] SangameswaraRaju, GudlaPardhasaradhi, "Optimal Design Planning of Ground Grid for Outdoor Substations in MEA's Power Distribution Substation", Journal of Engineering Research and Applications (IJERA) May-Jun 2012. 
Electrical and Electronics Engineering: An International Journal (ELELIJ) Vol 4, No 1, February 2015

[5] M.G. Unde, B.E. Kushare, Dr. VithalraoVikhePatil, "Grounding grid performance of substation in two layer soil-a parametric analysis", International Journal of Engineering Sciences \& Emerging Technologies, Feb 2012

[6] Puttarach,N. Chakpitak, T.Kasirawat and C.Pongsriwat,"Substation Grounding Grid Analysis with the Variation of Soil Layer Depth Method" IEEE PES International Conference Power Tech, Lausanne, Switzerland, July 2007.

[7] O.P. Rahi1, Abhas Kumar , Shashi Gupta \&ShilpaGoyal "Design of Earthing System for a Substation",International Journal of Advanced Computer Research, December2012.

[8] AttPhayomhom, SompornSirisumrannukul, Tirapong and ArwutPuttarach "Safety Design Planning of Ground Grid for Outdoor Substations in MEA's Power distribution system",ECTI transactions on electrical engg, electronics and communications ,February 2011

[9] S.Ghoneim, H.Hirsch, A. Elmorshedy, R.Amer, "Improved Design of Square Grounding Grids", International Conference of Power System Technology, Powercon 2006, Chongqing, China, Oct. 2006.

[10] E. Bendito,A.Carmona, A.M.Encinas, "The External Charges Method in Grounding Grid Design"

[11] Xun Long ,MingDong, WilsunXu, "Online Monitoring of Substation Grounding Grid Conditions Using Touch and Step Voltage Sensors", IEEE transactions on smart grid, vol. 3, no. 2, june 2012

[12] Y.L. Chow, M.M.A. Salama," A Simplified Method for Calculating the Substation Grounding Grid Resistance" IEEE Transactions on Power Delivery, Vol. 9, No. 2.

[13] Dwarka Prasad, H.C. Sharma," Significance of Step and Touch Voltages ", (IJSCE) ISSN: 22312307, Volume-1, Issue-5, November 2011.

[14] Chae-kyun Jung, Jong-kee Choi and Ji-won Kang,” A Study on Effects of Grounding Systems on Transient Voltages in $154 \mathrm{kV}$ Substation" IEEE T\&D Asia 2009

\section{Appendix}

The table of containing substation data is provided below:

\begin{tabular}{|c|c|c|}
\hline $\begin{array}{c}\text { Sr. } \\
\text { No }\end{array}$ & Description of Parameter & Value \\
\hline 1. & Level of Voltage & $500 \mathrm{KV}$ \\
\hline 2. & Maximum Fault Current & $40 \mathrm{KA}$ \\
\hline 3. & Ground Grid Mesh Area & $144 \times 100 \mathrm{~m}^{2}$ \\
\hline 4. & Ground grid mesh Horizontal Distance & $144 \mathrm{~m}$ \\
\hline 5. & Ground grid mesh Vertical distance & $100 \mathrm{~m}$ \\
\hline 6. & Horizontally Installed Conductors & 14 \\
\hline 7. & Vertically installed Conductors & 10 \\
\hline 8. & Conductors Area & $185 \mathrm{~mm}^{2}$ \\
\hline 9. & Conductors Type & Copper annealed Soft Drawn \\
\hline 10. & Maximum Temperature of conductors & $50 \mathrm{C} \circ$ \\
\hline 11. & Rods installed in vertical Direction & 50 \\
\hline 12. & Rod Diameter of Vertical Rods & 1.2 centimeter \\
\hline 13. & Rod & steel Rod Copper clad \\
\hline 14. & Duration of fault & $1 \mathrm{~second}$ \\
\hline 15. & Temperature Outside & $-5-50{ }^{\circ} \mathrm{C}$ \\
\hline 16. & Temperature of Rod & $50{ }^{\circ} \mathrm{C}$ \\
\hline 17. & X/R ratio Reactance over Resistance & 50 \\
\hline 18. & Person Weight & $50 \mathrm{~kg}$ \\
\hline 19. & soil Type at surface & gravel \\
\hline 20. & Resistivity & $9976 \Omega . \mathrm{m}$ \\
\hline
\end{tabular}


Electrical and Electronics Engineering: An International Journal (ELELIJ) Vol 4, No 1, February 2015

\begin{tabular}{|r|r|l|}
\hline 21. & Height & \multicolumn{1}{|c|}{$0.2 \mathrm{~m}$} \\
\hline 22. & Top Soil & Moist layer \\
\hline 23. & Resistivity & $130 \Omega \mathrm{hm}$. Meter \\
\hline 24. & Height & \\
\hline 25. & Soil bottom layer Type & Semi Moist soil \\
\hline 26. & Soil bottom layer Resistivity & \\
\hline 27. & Soil bottom layer Height & infinity \\
\hline 28. & Level of fault in relation to earth $\mathrm{S}_{\mathrm{f}}$ & \\
\hline 29. & Increase in fault level $\mathrm{C}_{\mathrm{p}}$ & \\
\hline
\end{tabular}

